\title{
AVALIAÇÃO DE SEMENTES FIRMES EM PENSACOLA BAHIA E MILHETO ${ }^{1}$
}

\author{
RAMIRO VILELA DE ANDRADE ${ }^{2}$ E CHARLES E. VAUGHAN ${ }^{3}$
}

RESUmo. Dez lotes de sementes de pensacola bahia (Paspalum notatum Flugge e de milheto (Panicum ramosum L.) foram avaliados pelo teste de germinação e pelo tratamento com ácido sulfúrico concentrado durante 20 minutos. No final do teste de germinação as sementes firmes viáveis (determinadas pelo teste de tetrazólio) foram adicionadas às sementes germinadas para determinar o potencial de germinação de cada lote de sementes. Paralelamente aos estudos de laboratório, foi instalado um experimento de campo para determinar o valor de plantio das sementes firmes. Nos lotes de sementes de pensacola bahia tratados com ácido sulfúrico concentrado, houve um aumento médio de $17,4 \%$ na germinação, em testes de laboratório. Entretanto, em testes de campo, sementes não tratadas, apresentaram- aos 38 dias após o plantio, um acréscimo de 6,4\% na emergência comparadas com as sementes tratadas com ácido. $\mathrm{O}$ uso do ácido sulfúrico no tratamento das sementes de pensacola bahia durante 20 minutos foi eficaz na quebra de suas dormências, e diminuiu em nove dias o tempo requerido para germinação. 0 teste de tetrazólio aplicado às sementes firmes de pensacola bahia 28 dias após terem sido submetidas ao teste de germinação, indicou que $70 \%$ das sementes firmes não tratadas e, $50 \%$ das sementes firmes tratadas com o ácido eram viáveis. A viabilidade total das sementes de cada lote de pensacola bahia não foi afetada pelo tratamento com o ácido, mas o seu uso aumentou o número de plântulas anormais. O tratamento das sementes de milheto com ácido sulfúrico concentrado durante 20 minutos, foi prejudicial para germinação tanto em condições de laboratório como de campo. Sementes de milheto tratadas com este ácido foram mais susceptíveis ao ataque de microorganismos e em conseqüência verificou-se um aumento no número de plântulas anormais. $\mathrm{O}$ aumento do tempo de tratamento de sementes de milheto com ácido sulfúrico de zero a 15 minutos, diminuiu a porcentagem

${ }^{1}$ Parte de tese apresentada pelo primeiro autor à Universidade do Estado do Mississippi, E.U.A., como uma das exigências do curso de Mestrado em Tecnologia de Sementes.

${ }^{2}$ Eng . Agro Pesquisador da EMBRAPA - Centro Nacional de Pesquisa de Milho e Sorgo - Caixa Postal 151 - 35700 - Sete Lagoas, MG.

${ }^{3} \mathrm{Ph} . \mathrm{D}$. Professor da Universidade Estadual do Estado do Mississippi, Lab. de Tecnologia de Sementes, P.O. Box 5267 - Miss. State, Miss., 39762 - USA. 
de germinação das sementes. Por outro lado a incidência de ataque de microorganismos e o número de plântulas anormais, aumentaram com o aumento do tempo de duração do tratamento com ácido.

Termos para indexação: sementes, pensacola bahia, milheto, semente firme, tratamento com ácido sulfúrico, germinação, emergência.

\title{
EVALUATION OF FIRM SEED IN PENSACOLA BAHIAGRASS AND BROWNTOP MILLET
}

\begin{abstract}
ABSTRACr. Ten lots of bahia grass seed (Paspalum notatum Flugge) and ten lots of browntop millet seed (Panicum ramosum L.) were evaluated by the standard germination test and by a 20 minute acid scarification treatment. Following the laboratory study a field experiment was also conducted to determine the planting value of each seed lot. Bahia grass seed lots showed an average increase of $17,4 \%$ in germination in the laboratory after acid scarification. However, non treated seed germinated, on the average $6,4 \%$ higher than acid scarified seed 38 days after planting. A 20 minute acid scarification treatment almost overcame dormancy in bahia grass. At the and of the 28-day germination test period, firm seeds were subjected to the tetrazolium test. Results showed that most of these seed were still viable ( $70 \%$ for un-scarified seed an $50 \%$ for acid-scarified seed). Total viability of the seeds was not affected by acid scarification treatment but the number of abnormal seedlings increased. The acid scarification method shortened the time required for germination by about nine days. A 20 minute sulfuric acid scarification treatment was detrimental to browntop millet in both laboratory and field tests. The number of abnormal seedlings was greatly increased and the seedlings were severely attacked by fungal organisms following the acid scarification treatment. The number of abnormal seedlings and degree of fungal attack were closely related to the time of sulturic acid treatment; as the time increased, abnormality increased.
\end{abstract}

Index terms - Seeds, pensacola bahia grass, browntop millet, firm seed, sulfuric acid treatment, germination, emergence. 


\section{INTRODUÇÃO}

A germinação de sementes de espécies forrageiras, tem sido em todo o mundo um sério problema encontrado pelos analistas de sementes e outros interessados na propagação dessas espécies.

As condições ambientais associadas à dormência das sementes são alguns dos fatores responsáveis para o sucesso no estabelecimento de pastagens.

Entre as gramíneas mais utilizadas como pastagens no sudeste dos Estados Unidos, encontram-se o milheto (Pañicum ramosum L.) e a pensacola bahia (Paspalum notatum Flugge) as quais são de difícil estabelecimento, devido a alta incidência de sementes dormentes. Esta dormência se prolonga por vários meses, e até anos, após a colheita (Burton 1940, Andersen 1953)

A maioria das gramíneas apresenta um tipo de dormência denominada "semente firme" que se caracteriza pela impermeabilidade do pericarpo a trocas gasosas do interior da semente com o meio exterior, embora estas sementes sejam capazes de absorver água o suficiente para germinar. As sementes de milheto e de pensacola bahia apresentam este tipo de dormência.

A quebra de dormência em sementes tem sido feita através de vários métodos e o tratamento com ácido sulfúrico tem sido mais eficaz. (Harrington 1918; Burton 1939; Williams e Webb 1958; Emal e Conard 1973; Feng, 1974 e Fernandes 1976).

Nakamura (1962), usou vários métodos para quebrar a dormência de sementes de Paspahum notatum. Ficou constatado que o emprego dos métodos: temperaturas alternadas, resfriamento, ácido nítrico e ácido sulfúrico, eram todos eficazes na quebra de dormència de sementes desta espécie: Contudo, quando se tratava de sementes com alta incidência de dormencia, era indicada a combinação desses quatro métodos para se obter uma germinação completa. Gupta (1973), constatou que somente a escarificação com ácido sulfúrico não foi suficiente para quebrar a dormência das sementes de certas gramíneas mas o pré-tratamento com este ácido, seguido do ácido giberélico uu resfriamento, acelerou o processo germinativo, elevando a germinação para $80 \%$ em nove dias, enquanto que o tratamento só com ácido sulfúrico, germinação só com ácido sulfúrico, germinou 34\% em 16 dias.

Gaber et alli (1974), citam que tanto o ácido sulfúrico como o ácido nítrico podem ser usados com sucesso na quebra de dormência de sementes de sorgo (Sorghum bicolor).

O objetivo deste experimento foi comparar em condições de laboratório e de campo, o índice de germinação e a velocidade de germinação de sementes de milheto e pensacola bahia escarificadas, e não escarificadas com ácido sulfúrico. Baseado 
neste estudo foi determinado o valor de plantio das sementes dormentes destas duas gramíneas.

\section{MATERIAL E MÉTODOS}

Foram utilizados, 10 lotes de sementes de Paspalum notatum Flugge e 10 lotes de Panicum ramosum L., colhidos em setembro e outubro de 1975 os quais foram armazenados em condições ambientais até maio de 1976. Foi realizada a pureza física destas amostras utilizando o General Seed Blower-ER, e daí por diante armazenadas em uma atmosfera controlada de $10^{\circ} \mathrm{C}$ e $50 \%$ de umidade relativa. As amostras de trabalho eram retiradas deste ambiente controlado, a medida que eram necessárias para os testes que consistiram em comparar em condições de laboratório e de campo, a germinação de sementes das duas espécies, tratadas e não tratadas com o ácido sulfúrico.

O tratamento com o ácido consistiu na imersão das sementes destas gramíneas em $25 \mathrm{~cm}^{3}$ de ácido sulfúrico concentrado (densidade 1,84) durante 20 minutos. A completa imersão das sementes foi feita utilizando-se um bastão de vidro. Após o tratamento, as sementes foram lavadas com água corrente, colocadas em um becker com água durante 10 minutos, envolvidas em um pedaço de gase, para retirar os traços do ácido. Em seguida foram secas em papel mataborrão por uma hora e postas para germinar. $\mathrm{O}$ período entre o tratamento com o ácido sulfúrico e a semeadura não ultrapassou uma semana.

\section{Testes de laboratório}

As sementes tratadas com ácido sulfúrico e as sementes não tratadas (controle) das duas espécies, foram levadas ao germinador em duas épocas (maio e setembro). Os testes foram conduzidos de acordo com as normas estipuladas nas Regras de Análise de Sementes (A.O.S.A. 1970) - Association of Official Seed Analysts sendo que, as contagens das plântulas foram feitas aos 7,14, 21 e 28 dias após a semeadura para pensacola bahia e aos 4 e 14 dias para o milheto.

No final do período estipulado para a germinação, as sementes de pensacola bahia que não germinaram foram submetidas a uma pressão utilizando uma espátula de metal. Aquelas que resistiram a pressão, "sementes firmes", foram submetidas ao teste de tetrazólio para determinar a sua viabilidade e adicionadas as sementes germinadas para determinar o potencial de viabilidade de cada lote. Tomaram-se as médias dos resultados obtidos das duas épocas as quais foram usadas nos cálculos.

Revista Brasileira de Sementes - Ano $2-n O 2-$ Brasilia-DF - 1980 


\section{Testes de cạmpo}

Os mesmos tratamentos usados no laboratório foram testados em condições de campo utilizando-se um delineamento experimental de blocos ao acaso com quatro repetições. Três semanas antes do plantio, o solo foi tratado com Vapam (metil carbamato de sódio, princípio ativo 32,7\%) na dosagem de $140 \mathrm{~cm}^{3}$ por metro quadrado, diluído em água para controlar invasoras. Foram plantadas 100 sềmentes em linha a uma profundidade de $1 \mathrm{~cm}$, espaçadas de $1 \mathrm{~cm}$ uma da outra. A distância entre linhas foi de $12 \mathrm{~cm}$.

As contagens de emergências das plântulas foram feitas aos $9,14,19,24,28$ e. 38 dias após o plantio para pensacola bahia e, aos 9, 14, 19 e 28 dias para o mi1heto. A última contagem foi feita arrancando-se as plantas para se ter a certez: de que estas eram provenientes das sementes, descartando os perfilhos que estavam começando a aparecer.

Em virtude do tratamento com ácido sulfúrico durante 20 minutos ter sido prejudicial para a germinação das sementes de milheto, tanto no teste de laboratório como no de campo, um outro experimento foi instalado para determinar o tempo ideal do uso deste ácido na escarificação das sementes desta espécie. Para o novo experimento foram utilizados os dois lotes de milheto, que apresentaram maiores índices de sementes dormentes nos testes do primeiro experimento e constiuiu-se no tratamento das sementes com ácido sulfúrico durante 0,$0 ; 1,0 ; 2,5$; 5,$0 ; 7,5 ; 10,0 ; 12,5$ e 15,0 minutos. O método de tratamento foi o mesmo anteriormente mencionado.

\section{RESULTADOS E DISCUSSÃO}

\section{Sementes de pensacola bahia}

Houve um aumento significativo na velocidade inicial de germinação das sementes tratadas com ácido sulfúrico comparadas com as não tratadas (Tabela 1). Em teste de laboratório, sementes tratadas com ácido sulfúrico, durante os sete primeiros dias de semeadura apresentaram uma germinação de $75,2 \%$, contra $8,2 \%$ obtidos nas sementes não tratadas durante o mesmo período. Contudo, esta diferença de germinação entre os dois tratamentos, foi diminuído gradativamente; aos 28 dias após a semeadura (final do experimento) foi de 17,4\% em favor das sementes tratadas com o ácido.

A emergência no campo durante os primeiros dias foi semelhante à obtida no laboratório (Tabela 1). Nove dias após o plantio, conștatou-se uma emergência 
de $45,4 \%$ nas sementes tratadas e de apenas $0,1 \%$ nas não tratadas. Como no teste de laboratório, esta diferença foi diminuindo gradativamente para equivalerem-se aos 28 dias após o plantio. No final do experimento (38 dias após o plantio), as sementes não tratadas apresentaram $6,4 \%$ a mais de emergência do que as sementes tratadas com o ácido. Contudo esta diferença está dentro das tolerâncias estipuladas nas Regras de Análises de Sementes (A.O.S.A., 1970).

Tabela 1. Porcentagens de germinação e de emergência de 10 lotes de sementes tratadas e não tratadas de pensacola bahia.

\begin{tabular}{|c|c|c|c|c|c|c|c|c|}
\hline \multirow{2}{*}{ Tratamentos } & \multicolumn{8}{|c|}{ Dias após a semeadura } \\
\hline & 7 & 9 & 14 & 19 & 21 & 24 & 28 & 38 \\
\hline Laboratório & & & & & & . & & \\
\hline Tratadas & 75,2 & - & 83,1 & - & 84,4 & - & 84,4 & - \\
\hline Não tratadas & 8,2 & - & 50,6 & - & 62,0 & - & 67,2 & - \\
\hline \multicolumn{9}{|l|}{ Campo } \\
\hline Tratadas & - & 45,4 & 57,8 & 61,4 & - & 61,5 & 62,3 & 62,9 \\
\hline Não tratadas & - & 0,1 & 13,6 & 41,9 & - & 50,6 & 60,0 & 69,3 \\
\hline
\end{tabular}

Fernandes (1976), trabalhando com a mesma espécie, salientou a vantagem de escarificação de sementes com ácido sulfúrico na obtenção de uma germinação com cinco a sete dias de antecedência quando comparadas com sementes não tratadas.

O tratamento das sementes de pensacola bahia com ácido sulfúrico praticamente superou a sua dormência. A média das sementes firmes, 28 dias após a semeadura foi de $22,8 \%$ nas sementes não tratadas e de apenas $0,4 \%$ nas sementes tratadas com o ácido (Tabela 2).

O teste de tetrazólio indicou que $70 \%$ das sementes firmes não tratadas e $50 \%$ das sementes firmes tratadas eram viáveis (Tabela 2).

A viabilidade total dos 10 lotes de sementes, não foi afetada pelo tratamento com ácido sulfúrico, embora o seu uso tenha comprovado um aumento de plântulas anormais (Tabela 2).

Fazendo-se a comparação de germinação no laboratório e no campo, constatou-se que as sementes tratadas com o ácido germinaram menổ $21.5 \%$ no campo. (Tabela 1). As sementes não tratadas apresentaram no campo uma emergéncia de 
2,1\% superior a germinação no laboratório. Contudo este acréscimo não foi significativo de acordo com as tolerâncias estipuladas nas Regras de Análises de Sementes (A.S.O.A. 1970).

O aumento do número de plântulas anormais nos lotes de sementes tratadas (Tabela 2), leva a crer que o uso do ácido sulfúrico prejudicou a germinação das sementes que provavelmente encontram-se livre de dormência.

Tabela 2. Porcentagens de germinação, plântulas anormais, sementes firmes e sementes firmes viáveis pelo teste de tetrazólio, de 10 lotes de sementes de pensacola bahia.

\begin{tabular}{|c|c|c|c|c|c|c|}
\hline \multirow[b]{2}{*}{ Tratamento } & \multicolumn{3}{|c|}{ Teste de Germinação } & \multicolumn{2}{|c|}{ Teste de Tetrazólio } & \multirow{2}{*}{$\begin{array}{l}\text { Viabilidade } \\
\text { total }\end{array}$} \\
\hline & $\begin{array}{l}\text { Plântulas } \\
\text { normais }\end{array}$ & $\begin{array}{l}\text { Plântulas } \\
\text { anormais }\end{array}$ & $\begin{array}{l}\text { Sementes } \\
\text { firmes }\end{array}$ & $\begin{array}{l}\text { Sementes } \\
\text { viáveis }\end{array}$ & $\begin{array}{l}\text { Sementes firmes } \\
\text { não viáveis }\end{array}$ & \\
\hline Tratadas & 84,6 & 3,6 & 0,4 & 0,2 & 0,2 & 84,8 \\
\hline Não tratadas & 67,2 & 2,1 & 22,8 & 15,7 & 7,1 & 82,9 \\
\hline
\end{tabular}

\section{Sementes de milheto}

Os dados apresentados na Tabela 3 , mostram as porcentagens de germinação das sementes de milheto tratadas e não tratadas, nas condições de laboratório e de campo.

No teste de laboratório, sementes não tratadas de milheto tiveram germinação superior as sementes tratadas tanto aos quatro como aos 14 dias. Até o final do teste (14 dias após a semeadura) apenas um adicional de $0,8 \%$ das sementes tratadas conseguiram germinar. No teste de campo, as sementes não tratadas apresentaram uma maior germinação no final do experimento $(81,7 \%$ para as sementes não tratadas e $66,3 \%$ para as sementes tratadas), embora houvesse uma germinação mais rápida nas sementes tratadas nos primeiros nove dias do plantio (Tabela 3).

Os resultados apresentados na Tabela 4 , indicam uma porcentagem média de sementes firmes de 5,5\% nas sementes não tratadas e zero nas sementes tratadas com ácido sulfúrico, 28 dias após a semeadura, em testes de laboratório. 
Tabela 3. Porcentagem média de germinação e emergência de $\mathbf{1 0}$ lotes de sementes de milheto tratadas e não tratadas.

\begin{tabular}{lccccc}
\hline & \multicolumn{5}{c}{ Dias após o plantio } \\
\cline { 2 - 5 } Tratamento & 4 & 9 & 14 & 19 & 28 \\
\hline Laboratório & & & & & \\
$\quad$ Tratadas & 69,0 & - & 69,8 & - & - \\
$\quad$ Não tratadas & 75,7 & - & 85,7 & - & \\
& & & & & \\
Campo & - & 61,8 & 63,0 & 68,2 & 66,3 \\
$\quad$ Tratadas & - & 45,2 & 78,7 & 80,2 & 81,7 \\
$\quad$ Não tratadas & & & & & \\
\hline
\end{tabular}

Os 10 lotes de sementes de milheto estudados, foram considerados ligeiramente dormentes, não apresentando problemas na germinação.

O número de plântulas anormais quadruplicou nas sementes tratadas, além de terem a sua viabilidade total diminuída (Tabela 4). As plântulas provenientes de sementes tratadas foram menos vigorosas, e em conseqüência mais susceptíveis ao ataque de microorganismos. Resultados semelhantes foram encontrados por Andersen (1958), que constatou a presença de Fusarium e Helminthosporium na germinação de duas espécies de milheto, causando problemas mais sérios na germinação do que a dormência das sementes em si.

Tabela 4. Porcentagens médias de germinação, plântulas anormais, sementes firmes e viabilidade total de 10 lotes de sementes de milheto tratadas e não tratadas.

\begin{tabular}{lcccc}
\hline Tratamento & Germinação & $\begin{array}{c}\text { Plântulas } \\
\text { anormais }\end{array}$ & $\begin{array}{c}\text { Sementes } \\
\text { firmes }\end{array}$ & $\begin{array}{c}\text { Viabilidade } \\
\text { total }\end{array}$ \\
\hline Tratadas & 69,8 & 4,3 & 0,0 & 69,8 \\
Não tratadas & 85,7 & 1,0 & 5,5 & 91,2 \\
\hline
\end{tabular}


Ficou evidenciado, neste trabalho, que o tratamento com ácido sulfúrico durante 20 minutos foi prejudicial para a germinação das sementes de milheto. Baseando-se nestes resultados, foi conduzido um outro experimento de laboratório, para determinar o período ideal de tratamento das sementes dessa espécie com ácido sulfúrico concentrado.

Foi verificado neste experimento, que o tratamento das sementes de milheto com ácido sulfúrico não aumentou a sua germinação em nenhum dos períodos estipulados (Tabela 5). Por outro lado, aumentando o período de tratamento das sementes com o ácido sulfúrico elevou a porcentagem de plântulas anormais.

$\mathrm{O}$ aumento do período de tratamento com o ácido também provocou uma redução da porcentagem de germinação e uma maior incidência de microorganismos.

Tabela 5. Efeito do tratamento de dois lotes de sementes de milheto com ácido sulfúrico na porcentagem de germinação.

\begin{tabular}{lrrrrrrrr}
\hline & \multicolumn{8}{c}{ Tempo em minutos } \\
\cline { 2 - 9 } & 0,0 & 1,0 & 2,5 & 5,0 & 7,5 & 10,0 & 12,5 & 15,0 \\
\hline Germinação & 74,9 & 67,8 & 73,5 & 75,6 & 68,4 & 70,4 & 70,0 & 65,2 \\
$\begin{array}{l}\text { Plântulas } \\
\text { anormais }\end{array}$ & 1,8 & 3,7 & 3,0 & 3,1 & 2,7 & 3,5 & 3,8 & 4,4 \\
$\begin{array}{l}\text { Sementes } \\
\text { firmes }\end{array}$ & 10,7 & 6,1 & 4,4 & 2,5 & 1,4 & 0,5 & 0,0 & 0,0 \\
$\begin{array}{l}\text { Germinação } \\
\text { mais sementes firmes }\end{array}$ & 85,6 & 73,9 & 78,1 & 78,1 & 69,8 & 70,9 & 70,0 & 65,2 \\
\hline
\end{tabular}

\section{CONCLUSÕES}

A escarificação com ácido sulfúrico não aumentou a germinação das sementes de pensacola bahia e de milheto. No entretanto, convém ressaltar que as sementes utilizadas no presente trabalho não apresentaram dormência elevada. Estudos mais detalhados são necessários em lotes de sementes destas duas espécies que se apresentem severamente dormentes. Baseado nos rèsultados, conclui-se que não houve um valor de plantio das sementes firmes destas gramíneas. A vantagem da escarificação com ácido sulfúrico de lotes de sementes com dormência não muito elevada, foi a redução do período de emergência de nove dias em ambas as espécies tratadas. 


\section{REFERENCIAS}

ANDERSEN, A.M. The effect of the glumes of Paspalum notatum lilugge on germination. Proc. Assoc. Off. Seed Anal., 43: 93-100, 1953.

A preliminary study of dormancy in browntop and cattail millets. Proc. Assoc. Off. Seed Anal., 48: 85-92, 1958.

ASSOCIATION OF OFFICIAL SELD ANALYSTS. Rules for testing seeds. Proc. Assoc. Off. Seed Anal., 60 (2): 1-116, 1970.

BURTON, G.W. Scarification studies on Southern grass secd. J. Am. Soc. Agron., 31 : 179-87, 1939.

The stablishement of bahiagrass (Paspalum notatum, Flugge). J. Am. Soc. Agron., $32: 545-9,1940$.

EMAL, J.C. \& CONARD, E.C. Seed dormancy and germination in indiangrass as affected by light, chilling, and certain chemical treatments. Agron. J., 65 (3): 385-5, 1973.

FENG, J.G. Seed dormancy in johnsongrass, argentine bahiagrass and pensacola bahiagrass. Mississippi, Mississippi State University, 1974. (Thesis, M. Sc.)

FERNANDES, G.M.B. Methods for overcoming seed dormancy in pensacola bahiagrass (Paspalum notatum, Flugge), Mississippi, Mississippi State University, 1976. (Thesis M. Sc.).

GABER, S.D.; ABDALLA, F.H. \& MAHDY, M.T. Treatments affecting dormancy in sweet sorghum seed. Proc. Int. Seed Test. Assoc., 1(3): 305-16, 1974.

GUPTA, K.C. Factors influencing dormancy in seeds of crowfootgrass. Biochem Physiol. Pflan* zen (Bpp). 164:582-7, 1973.

HARRINGTON, G.T. Germination and viability of johnsongrass seed. Proc. Assoc. Off. Seed Anal. Anal. 6: 24-48, 1918.

NAKAMURA, S. Germination of grass seeds. Proc. Int. Seed. Test. Assoc., 27 (3): 710-29, 1962.

WILLFAMS, R.C. \& WEBB, B.C. Seed moisture relationships and germination behavior of acid scarified bahiagrass seed. Agron. J., 50: 235-7, 1958. 